\title{
Philosophical Thinking on the Application of ISO9000 Quality Man- agement System
}

\author{
Yi Wang*
}

Zhejiang Ocean University Donghai Science and Technology College, Zhoushan 316000, China. E-mail: 1315713580@qq.com

Abstract: This paper learned the application of ISO9000 quality management system in China and made the philosophical reflection in the research of philosophy of quality management system, to explore the quality management system that have promote and inhibit functions from the perspective of philosophical contradiction for the food industry, emphasized the practical significance in the food industry, finally in the quality management system under the perspective of the dialectical unification of truth and value the development of food industry are analyzed.

Keywords: ISO9000 Quality Management System; Food; Industry Philosophy

\section{Connotation and implementation status of ISO9000 quality manage- ment system}

"The food to Ann first", the question of product quality management has been the focus of food industry, and the ISO9000 system is strives for the survival by the quality, has been the quality strives for the development, to the quality and efficiency of the fundamental principles of quality management system, also has experienced several quality management and quality management system development stage, from the product quality inspection, statistical quality management, total quality management stage to the standardized quality management stage, the development of the quality management system to control the product quality played a key role.

\subsection{Connotation of ISO9000 quality man- agement system}

ISO9000 defines a management system as a system which tries to establish policies and objectives and achieve those objectives. And ISO9000 is not a standard but a standard set of a general designation, including the ISO9000 quality management system and the basis of the terms, ISO9001 quality management system and ISO9004 guidelines for quality management system performance improvement, and the ISO9000 family of standards is a set of practical management mode, the management mode of industrial developed countries are summarized the successful experience of the advanced enterprise of quality management, make the national quality management and quality assurance activities unified on the basis of the ISO90000 clan standard. To carry out and pass the certification of ISO9001 standard is the embodiment of modern enterprises to establish a scientific management system ${ }^{[1]}$.

Copyright (C) 2021 Yi Wang

doi: 10.18686/fsr.v3i1.1360

This is an open-access article distributed under the terms of the Creative Commons Attribution Non-Commercial License

(http://creativecommons.org/licenses/by-nc/4.0/), which permits unrestricted non-commercial use, distribution, and reproduction in any medium, provided the original work is properly cited. 


\subsection{Current situation of ISO9000 quality management system}

In 1987, the first series of quality assurance standards-ISO9000 family standards were released, which opened the prelude of standardized quality management, and made great improvement and great progress in a short period of more than ten years.

The second edition was published in 1994, the third edition in 2000, the fourth edition in 2008 and the fifth edition in 2015. In our country before 1995, ISO9000 quality management system just introduced, few organization certification. 1995-2005, steady development period, certification of large organizations. After 2006, blowout type development.

ISO9001 certification is known as the "passport to the international market", and has become a sign that organizations have the ability to provide products or services with specified requirements ${ }^{[2]}$.

\section{Value analysis of ISO9000 quality management system application}

Management system for the development of food industry plays an important guiding role, but managers in transforming a subjective and objective object, we need to look at the issue with dialectical thinking, he is good for the food industry plays a role at the same time, also continues to impact the existing traditional food management mode, therefore, we want to be in play the effective role at the same time reduce the adverse effect.

\subsection{Positive value analysis of ISO9000 quali- ty management system}

With the ever-increasing of people's living standard, people have higher and higher requirements on the quality of life. However, there is no unified system management in the food industry, leading to a series of food safety problems ${ }^{[3]}$ Yan Jing. The problem, has caused certain influence to people's life, but at this time the development of science and technology also unceasingly solves the difficult problem for the human development, on the appearance of ISO9000, may say has produced the huge guidance function to the human society's development.

Quality management system to the scope and purpose of the activities, what to do, who will do, when to do and where to do, how to do, use what equipment and materials, such as how to control and record the activities make the detailed rules, which is clearly the management responsibilities and work procedures, each work rules-based, promote enterprise management from the "rule of man" to "rule of law"[4]. The enterprise has obtained ISO9001 certification, which also means that the enterprise has established a set of perfect quality management system in all aspects, such as management, practical work, relationship between suppliers and distributors, products, market and after-sales service. And through a series of carrying out the ISO9000 standard, implementation and certification, continuous operation and other activities, the management of the staff quality was improved, the enterprise standard management consciousness enhanced, and establish the self-discovery problem, self-improvement, self-improvement mechanism, make the food industry to effectively control the quality of food, to reshape the effect on the food industry.

\subsection{Negative value analysis of ISO9000 qual- ity management system}

The implementation of ISO9000 quality management system may curtail the development of quality management, inhibits the development of its diversity, and for some small businesses to implement ISO9000 quality management system for its production process has certain difficulty, create constant pressure to the development of it, and the certification of ISO9000 system certification bodies need approval from the state, so the certification bodies can authenticate is less, easy to cause certain monopoly, caused a series of poor results. Philosophical reflection is showed on ISO9000 quality management system. Taking a philosophical view of the ongoing operation of the quality management system, we will find that the relationship between the food production industry and the management system is diverse from different perspectives. The following aspects are explained $^{[5]}$.

\section{Philosophical reflection on ISO9000 quality management sys- tem}

Taking a philosophical view of the ongoing opera- 
tion of the quality management system, we will find that the relationship between the food production industry and the management system is diverse from different perspectives. The following aspects are explained.

\subsection{Food quality management system from the perspective of contradiction}

There are contradictions between the food quality management system and the food industry. At the same time, we should look at the relationship between these contradictions from the perspective of contact.

\subsubsection{The prevalence of problems in the food production industry}

Since its birth, the food production industry has been filled with a variety of problems, that is, in the process of food production, processing, packaging, storage, circulation and consumption, in the face of a variety of food contamination risks, in the production and processing of personnel technical level and food industry management problems. But with the continuous development of science and technology, the old problems have been solved.

In the course of the development of contradiction, the universality of contradiction means that contradiction exists in the development of all things, and always exists in the development of all things, that is, there is contradiction in everything, and there is contradiction all the time. The universality of contradiction is universal and absolute to things. In the food production industry, the universality of contradictions is reflected in the fact that every step in the food production industry has some contradictions that may cause huge problems. There are contradictions in everything. And in the process of food production, there will be different contradictions due to different circumstances, which means there are always contradictions. And the characteristics of the ISO9000 quality management system is the basis rather than the top, make a food production process based quality management system, in the face of this everything is contradictory problem, to curb the beginning of the contradictions appear, reducing food production and the problems that may occur in the process of sale, reduce the occurrence of a common problem, and the resulting other problems.

\subsubsection{Look at the food industry from a rela- tional perspective}

Food industry is a complex whole, with its large-scale production level is higher and higher, the processing technology and equipment is more and more high xinhua, modern food production industry internal links between the two with enhanced, as on the basis of modern science, technology and engineering, to food production, processing, packaging, storage, circulation, consumption, environmental protection as the main research content of a business ${ }^{[6]}$.

In contradiction, the connotation of connection refers to the relationship of mutual influence, interaction and mutual restriction among all elements and things inside things. The food industry in the process of continuous development in the universal connection, this is the connection between the objectivity and universality. There are all kinds of connections, and that's the diversity of connections. Conditions on the development and support or restricting effects of human activities, the connection between the food industry internal interlocking, have a good contact also has a bad contact, before the application of ISO9000 quality management system, although there are a variety of food industry, but its existence and the condition of contact is complicated, after the application of ISO9000 quality management system, contact between the headless koala no longer, this is the emergence of the ISO9000 quality management system has broken the original complex connection, the connection between things displayed through system. It solves the problem of not being able to find the source of the problem, which is conditional on the connection ${ }^{[7]}$. The interrelation of things contains the interaction of things, and the interaction of things will inevitably cause the movement, change and development of things. Therefore, the successful application of this system leads the food industry product standard system and quality control system more and more perfect.

\subsection{Food quality management system from the perspective of practice}

Quality management system is a generic universal request. The system involved in the organization's policy objectives, organization and management, its purpose is to formal organization has the ability to steadily provide products meet customer and regulatory requirements, through the effective application system, including continual improvement and prevention of unqualified and enhance customer satisfaction. 
And to do the quality management system as the most important thing is practice, practice is the source of knowledge, only by applying quality management system, the real-time operation, can effectively recognize and confirm the application of the system will appear problem, and the reasonable solution for the management of food industry and can further understanding, namely the development of the practice continuously put forward the new subject of understanding ${ }^{[8]}$, push forward the recognition. This shows that practice is the driving force of cognitive development. The system first published since 1987, has experienced several changes, until today has published 2015 edition, the system of succession, exercise and improve the cognition of the subject, since then, ISO9001 certification in our country is known as "pass towards the international market", but also the introduction of more complex system of HACCP and ISO22000 system, and ISO22000:2005 adopted the ISO9000 system structure, applying HACCP principle as a method to the system as a whole. The system of the food industry has been effectively applied and this shows that practice is the purpose of cognition.

\subsection{Pursue the dialectical unity of truth and value under the quality management system}

Truth is correct reflection that a person to the objective things, the law of nature. Value is the object of the subject need satisfaction, quality management system in the process of continuous practice more and more close to the truth, and the resulting resource utilization management system makes the modern food industry is more and more reasonable, degree of finish machining and by-products utilization level is higher and higher, the product standard system and quality control system is more and more perfect, embodies the fair value of the quality management system, and the dialectical unification of truth and value embodiment is that in order to meet the needs of their own survival and development, people must transform the world, through practice in the process.

We should not only pursue the truth problem consistent with the subjective and objective, but also understand and transform the value problem of the world according to the needs and standards of the subject.

Here, the food industry in the process of development with quality management system, quality manage- ment system on behalf of the interests of the consumer and represents the interests of the producers of the contradiction between, contact and interaction with each other, caused by the movement of things, change and development, quality management system in the process of constantly development, between the subjective and objective and reasonable for the implementation.

\section{Conclusion}

The development and application of ISO9000 quality management system is a revolutionary change in the food industry. It makes the quality management of the food industry greatly improved and people's food safety is guaranteed to some extent.

After the ISO9000 quality management system, at the same time, people also developed other more complex quality management system, the management of the food industry is the scale of the control, however, the application of quality management system for the food industry in our country is still a challenge, in the face of the good and bad are intermingled in the food industry, still need to strengthen the implementation of the system.

There are still many shortcomings in this paper: first, the philosophical analysis of the quality management system is not in-depth enough, covering a wide range, there is no in-depth analysis; second, the grasp and choice of materials is not mature enough, did not put forward more examples to illustrate the problem.

\section{References}

1. Yan J. Philosophical analysis of food safety issues (in Chinese). Guide to Business 2011; (15): 241242.

2. Wang L. Philosophical exploration of transgenic technology [master's thesis]. Guangzhou: Party School of the Guangdong Provincial Committee of CPC; 2018.

3. Geng S. The STS perspective on food safety of philosophical thinking [master's thesis]. Shenyang: Shenyang University of Technology; 2015.

4. Zhao J. Research on green marketing from the perspective of philosophy of technology (in Chinese) [master's thesis]. Yunnan: Yunnan Normal University; 2013.

5. Shao Y. Research on the rule of law of food safety science and technology in China from the perspective of philosophy of science and technology (in Chinese) [master's thesis]. Yunnan: Yunnan Normal University; 2013. 
6. Chen W. Philosophical considerrations about food additives' application [master's thesis]. Wuhan: Wuhan University of Science and Technology; 2006.

7. Li Z. Philosophical reflections on green technology (in Chinese) [master's thesis]. Shenyang: Shenyang Normal University; 2016.

8. Hong L. The philosophical thinking toward problems of genetically modified crops [master's thesis]. Chengdu: Chengdu University of Technology; 2015. 